\title{
Uji Park Dan Uji Breusch Pagan Godfrey Dalam Pendeteksian Heteroskedastisitas Pada Analisis Regresi
}

\author{
Siska Andriani \\ UIN Raden Intan Lampung: siskaandriani@ radenintan.ac.id
}

\begin{abstract}
The purpose of this study was to obtain an overview of the detection of heteroscedasticity through the parkfrey test and pagan breeding tests in the regression analysis, which of the two tests were more effective. Research methods using qualitative research methods. The type of qualitative research method used is a type of development study research method. The development study referred to is to obtain a developmental picture of the two tests, namely the parkfitness test and the godfrey pagan breed test in the detection of heteroscedasticity in regression analysis through cross sectional method. Based on the results of detection studies in three data cases, two data were obtained which were tested by testing detected heteroscedasticity problems. Others there was one case that detected heteroscedasticity with the godfrey pagan breed test, but for the case with an undetectable park test. The results of the mean square error (MSE) obtained through the godfrey pagan breed test were smaller than the park test. It can be concluded that the godfrey pagan breeding test is more effective to use, compared to the park test in detecting heteroscedasticity in regression analysis. This means that in detecting the hetereoskedasticity problem, it is better to use the godfrey pagan breed test because it has better accuracy than the park test.
\end{abstract}

Keywords: Analysis; Breusch; Regression; Heteroscedasticity

\begin{abstract}
Abstrak
Tujuan penelitian ini adalah untuk memperoleh gambaran mengenai pendeteksian heteroskedastisitas melalui uji park dan uji breusch pagan godfrey pada analisis regresi, diantara keduanya uji manakah yang lebih efektif. Metode penelitian dengan menggunakan metode penelitian kualitatif. Adapun jenis metode penelitian kualitatif yang digunakan merupakan jenis metode penelitian studi perkembangan. Studi perkembangan yang dimaksud adalah untuk memperoleh gambaran perkembangan dari kedua uji, yaitu uji park dan uji breusch pagan godfrey dalam pendeteksian heteroskedastisitas pada analisis regresi melalui metode cross sectional. Berdasarkan hasil penelitian pendeteksian pada tiga kasus data, diperoleh dua data yang di uji dengan uji terdeteksi masalah heteroskedastisitas. Lainnya terdapat satu kasus yang terdeteksi heteroskedastisitas dengan uji breusch pagan godfrey, namun untuk kasus dengan uji park tidak terdeteksi. Diperoleh hasil nilai mean square error (MSE) melalui uji breusch pagan godfrey lebih kecil dibandingkan dengan uji park. Dapat disimpulkan bahwa uji breusch pagan godfrey lebih efektif digunakan, dibandingkan dengan uji park dalam pendeteksian heteroskedastisitas pada analisis regresi. Artinya dalam mendeteksi masalah hetereoskedastisitas, sebaiknya menggunakan uji breusch pagan godfrey karena mempunyai ketelitian yang lebih baik dibandingkan uji park.
\end{abstract}

Kata Kunci : Analisis; Breusch; Regresi; Heteroskedastisitas

\section{PENDAHULUAN}

Pentingnya analisis regresi dalam pendeteksian heteroskedastisitas. Analisis regresi merupakan analisis statistik yang digunakan untuk mengetahui adanya keterkaitan antara satu 
variabel tak bebas dengan satu atau lebih variabel bebas, juga mempelajari bagaimana membangun sebuah model fungsional dari data untuk dapat menjelaskan satu fenomena alami atas fenomena yang lain (Davino, 2014; Ratnasari, 2014; Muliawan, 2015). Model regresi linear dapat berupa garis lurus antara variabel tidak bebas dengan satu variabel bebas yang disebut garis regresi linear sederhana (simple linear regression) (Birkes, 2011; Hollander, 2015), jika dikembangkan dengan beberapa variabel bebas maka model regresi tersebut dikenal dengan garis regresi linear berganda (multiple linear regression) yang dinyatakan dengan persamaan umum: (Pradawati, 2013; Farizal, 2014; Sunarto, 2015; Nurlaila, 2017).

$Y=\beta_{0}+\beta_{1} X_{1}+\beta_{2} X_{2}+\cdots+\beta_{k} X_{k}+\varepsilon$. Jika analisis melibatkan satu variabel bebas, maka analisis yang digunakan adalah regresi linear sederhana. Sedangkan jika melibatkan lebih dari satu (minimal dua) variabel bebas, maka analisis yang digunakan adalah regresi linear ganda (multipel regression) (Sunarto, 2015). Proses pengujian asumsi klasik dilakukan bersama dengan proses uji regresi sehingga langkah-langkah yang dilakukan dalam pengujian asumsi klasik menggunakan langkah kerja yang sama dengan uji regresi. Ada lima uji asumsi yang harus dilakukan terhadap suatu model regresi tersebut yaitu uji normalitas, uji autokorelasi, uji linieritas, uji multikolinearitas, dan uji heteroskedastisitas. Analisis regresi, metode yang digunakan untuk melakukan estimasi parameter adalah metode kuadrat terkecil (MKT). Prinsip dari metode ini adalah meminimumkan jumlah kuadrat error (residu) (Ivan, 2016). Namun, terdapat beberapa asumsi di dalam analisis regresi yang harus dipenuhi dalam melakukan estimasi dengan metode kuadrat terkecil. Asumsi tersebut salah satunya homoskedastisitas. Homoskedastisitas merupakan asumsi penting yang harus dipenuhi yang berarti bahwa varian dari error bersifat konstan. Asumsi ini menyatakan bahwa peubah respon memiliki varian yang sama sepanjang nilai peubah bebas, pelanggaran terhadap asumsi homoskedastisitas (Tayeb, 2012; Uthami, 2013). Mengingat pentingnya analisis regresi pada suatu data, maka perlu dideteksi apakah terjadi heterokedastisitas dan bagaimanakah cara mendeteksi heteroskedastisitas data tersebut. Uji heteroskedastisitas yang dilakukan bertujuan untuk menguji apakah dalam model regresi tersebut memiliki varian yang konstan dari residual atau error antara satu pengamatan ke pengamatan yang lain (Uthami, 2013). Konsekuensi adanya heteroskedastisitas dalam model regresi adalah estimator yang diperoleh tidak efisien. Jika terjadi masalah heteroskedastisitas diperlukan penyembuhan agar diperoleh persamaan yang tepat. Menurut Ghozali (2009:36) ada dua cara untuk mendeteksi ada tidaknya heteroskedastisitas, yaitu metode grafik dan metode uji statistik. Terkait pendeteksian heteroskedastisitas tentu saja harus disesuaikan dengan uji statistik yang digunakan (Hajarisman, 2012). Terdapat beberapa uji statistik yang digunakan dalam pendeteksian ada tidaknya heteroskedastisitas, diantaranya uji park dan uji breusch pagan godfrey.

Uji park merupakan metode grafik plots dengan menyatakan bahwa variance $\sigma_{i}{ }^{2}$ dengan fungsi dari variabel-variabel independen $X_{\mathrm{i}}$ yang dinyatakan dalam persamaan berikut ini. $\sigma_{i}^{2}=\sigma^{2} X_{i}^{\beta} e^{V_{i}}$ (5). Persamaan ini dijadikan linear dalam bentuk persamaan logaritma natural sehingga menjadi $\ln \sigma_{i}^{2}=\ln \sigma^{2}+\beta \ln X_{i}+V_{i} \ln e \Leftrightarrow \ln \sigma_{i}^{2}=\ln \sigma^{2}+\beta \ln X_{i}+$ 
$V_{i}$ (1.6). Oleh karena variance $\sigma_{i}^{2}$ umumnya tidak diketahui, maka dapat ditaksir menggunakan residual $e_{i}^{2}$ sebagai proksi, sehingga persamaan menjadi $\ln e_{i}^{2}=\ln \sigma^{2}+$ $\beta \ln X_{i}+V_{i} \Leftrightarrow \ln \sigma_{i}^{2}=\alpha+\beta \ln X_{i}+V_{i}$ (1.7). Adapun langkah-langkah hipotesis pada uji park adalah sebagai berikut :

a. Rumusan hipotesisnya:

$\mathrm{H}_{0}$ : variansi galat bersifat homoskedastisitas atau $\operatorname{var}\left(e_{\mathrm{i}}\right)=\sigma^{2}$

$\mathrm{H}_{1}$ : variansi galat bersifat heteroskedastisitas atau $\operatorname{var}\left(e_{\mathrm{i}}\right) \neq \sigma^{2}$

b. Menentukan taraf signifikansi $\alpha$

c. Statistik uji $\mathrm{t}=\frac{\widehat{\beta}_{i}}{S e_{\beta}}$

d. Kriteria keputusan: $\mathrm{H}_{0}$ ditolak jika $\left|t_{\text {hitung }}\right|>t_{\frac{\alpha}{2} ;(n-p)}$, atau nilai Sig. $<\alpha$.

e. Langkah-langkah perhitungan uji park meliputi:

1) Melakukan estimasi pada persamaan regresi linear berganda yaitu:

(1.8) $Y_{i}=\beta_{0}+\beta_{1} X_{1 i}+\beta_{2} X_{2 i}+\ldots+\beta_{k} X_{k i}+e_{i}$

Sehingga diperoleh persamaan regresi dan residualnya.

(2) Mengkuadratkan dan log residualnya.

(3) Melakukan estimasi residual untuk memperoleh persamaan

$$
\ln \hat{e}_{i}^{2}=\ln \beta_{0}+\beta_{1} \ln X_{1 i}+\beta_{2} \ln X_{2 i}+\ldots+\beta_{k} \ln X_{k i}+\varepsilon_{i}
$$

f. Melakukan penarikan kesimpulan

Jika nilai $\beta$ signifikan secara statistik, berarti $X$ mempengaruhi $e_{i}^{2}$, maka $\mathrm{H}_{0}$ ditolak, dan $\mathrm{H}_{\mathrm{a}}$ diterima yang berarti mengindikasikan terjadi heteroskedastisitas, dan sebaliknya jika $\beta$ tidak signifikan maka $\mathrm{H}_{\mathrm{o}}$ diterima, dan model regresi homoskedastisitas. Adapun dengan uji breusch pagan godfrey (BPG), sebagaimana menurut Ghozali (2009:49), keterbatasan uji goldfeld quandt dapat dihindari dengan uji breusch pagan godfrey (BPG). Keberhasilan uji Goldfeld-Quandt tidak hanya tergantung dari nilai $c$ tetapi juga mengidentifikasi variabel $X$ yang mana yang akan di ranking secara benar. Misalkan terdapat model regresi linear dengan $n$-variabel independen: $Y_{i}=\alpha+\beta_{1} X_{1 i}+\beta_{2} X_{2 i}+\ldots+\beta_{n} X_{n i}+e_{i}$. Diasumsikan error variance $\sigma_{i}^{2}$ adalah sebagai berikut (1.11) $\sigma_{i}^{2}=f\left(\alpha_{1}+\alpha_{2} Z_{2 i}+\ldots+\alpha_{m} Z_{m i}\right) \Leftrightarrow \sigma_{i}^{2}=\alpha_{1}+\alpha_{2} Z_{2 i}+\ldots+\alpha_{m} Z_{m i}$. Dimana $\sigma_{i}^{2}$ merupakan fungsi linear dari Z jika $\alpha_{2}=\alpha_{3}=\ldots=\alpha_{m}=0$, maka $\sigma_{i}^{2}=\alpha_{1}$ yang merupakan konstanta. Jadi untuk menguji apakah $\sigma_{i}^{2}$ homoskedastisitas. Maka kita menguji hipotesis bahwa $\alpha_{2}=\alpha_{3}=\ldots=\alpha_{m}=0$. Adapun langkah-langkah yang digunakan untuk mendeteksi heteroskedastisitas dengan menggunakan Uji bruesch pagan godfrey. adalah sebagai berikut:

a. Lakukan regresi OLS persamaan $Y_{i}=\alpha+\beta_{1} X_{1 i}+\beta_{2} X_{2 i}+\ldots+\beta_{n} X_{n i}+e_{i}$ sehingga didapat nilai residualnya dan mencari $\sigma^{2}=\frac{\sum \hat{e_{i}^{2}}}{n}$ 
b. Mencari $p_{i}$ yang didefinisikan sebagai : $p_{i}=\frac{e_{i}^{2}}{\sigma^{2}}$

c. Regresi $p_{i}$ terhadap variabel Z sebagai berikut : (1.12) $\quad p_{i}=\alpha_{0}+\alpha_{1} Z_{i}+v_{i}$.

d. Dapatkan ESS (explained sum of square) dari persamaan (4.12) dan kemudian dapatkan $\phi=\frac{1}{2}(E S S)$.Jika residual di dalam persamaan terdistribusi normal maka 1/2 (ESS) akan mengikuti distribusi chi-square $\left(\chi^{2}\right)$ sebagai berikut $: \phi=\frac{1}{2}(E S S) \approx \chi_{d f}^{2}$

Pada penelitian sebelumnya terdapat pendeteksian heteroskedastisitas dengan berbagai uji statistik pada uji regresi (Birkes, 2011; Davino, 2014; Hollander, 2015; Nurlaila, 2017).

Berdasarkan uraian tersebut, maka dapat dirumuskan bahwa penelitian ini dilakukan dengan keterbaruan untuk mengetahui hasil pendeteksian heteroskedastisitas dengan uji park dan uji breusch pagan godfrey diantara keduanya manakah yang lebih efektif digunakan.

\section{METODE PENELITIAN}

Metode penelitian dengan menggunakan metode penelitian kualitatif. Adapun jenis metode penelitian kualitatif yang digunakan merupakan jenis metode penelitian studi perkembangan. Studi perkembangan yang dimaksud adalah untuk memperoleh gambaran perkembangan dari kedua uji, yaitu uji park dan uji breusch pagan godfrey dalam pendeteksian heteroskedastisitas pada analisis regresi melalui metode cross sectional.

\section{HASIL PENELITIAN DAN PEMBAHASAN}

Pendeteksian heteroskedastisitas dalam penelitian ini dilakukan dengan dua cara yakni dengan metode grafik dan metode uji statistik. Adapun untuk uji yang digunakan adalah uji park dan uji breusch pagan godfrey. Selanjutnya akan dijelaskan mengenai hasil penelitian dan pembahasan yang difokuskan pada data yang mempunyai kecenderungan untuk terjadi heteroskedastisitas beserta analisis contoh kasus pada beberapa data yang mengandung masalah heteroskedastisitas yang dideteksi dengan uji park maupun uji breusch pagan godfrey $R \& D=\beta_{0}+\beta_{1}$ Sales $+\beta_{2}$ Profi. Berdasarkan data tersebut, akan dilakukan pengecekan apakah mengandung heteroskedastisitas atau tidak jika dideteksi dengan kedua uji tersebut. Dengan bantuan sofware SPSS diperoleh persamaan regresi $R \widehat{\&} D=-13,956+$ 0,01 Sales + 0,24 Profit.

Pendeteksian dengan uji park sebagai berikut :

a. Rumusan hipotesis

$\mathrm{H}_{0}$ : variansi galat bersifat homoskedastisitas atau $\operatorname{var}\left(e_{i}\right)=\sigma^{2}$.

$\mathrm{H}_{1}$ : variansi galat bersifat heteroskedastisitas atau $\operatorname{var}\left(e_{i}\right) \neq \sigma^{2}$.

b. Menentukan taraf signifikansi $\alpha=0,05$.

c. Statistik uji $\mathrm{t}=\frac{\hat{\beta}_{i}}{\operatorname{Se}\left(\hat{\beta}_{i}\right)} ; t_{\frac{0,05}{2} ;(18-3)}=2,132$. 
d. Kriteria keputusan : $\mathrm{H}_{0}$ ditolak jika $\left|t_{\text {hitung }}\right|>t_{\frac{\alpha}{2} ;(n-p)}$, atau nilai Sig. $<\alpha$.

e. Langkah-langkah perhitungan uji Park dengan menggunakan Software SPSS sebagai berikut :

(1) Meregresikan variabel R \& D dengan variabel independen sales dan profit. Diperoleh persamaan regresi

$$
R \widehat{\&} D=-13,956+0,01 \text { Sales }+0,24 \text { Profit } .
$$

(2) Mengkuadratkan dan menghitung nilai log residualnya.

(3) Meregresikan variabel $\ln \hat{e}_{i}^{2}$ dengan variabel independen ln sales dan ln profit Sebagaimana pada Tabel 1.

Tabel.1

\begin{tabular}{|c|c|c|c|c|c|c|}
\hline \multicolumn{7}{|c|}{ Coefficients $^{\mathrm{a}}$} \\
\hline \multirow{2}{*}{\multicolumn{2}{|c|}{ Model }} & \multicolumn{2}{|c|}{$\begin{array}{l}\text { Unstandardiz ed } \\
\text { Coefficients }\end{array}$} & \multirow{2}{*}{$\begin{array}{c}\begin{array}{c}\text { Standardized } \\
\text { Coefficients }\end{array} \\
\text { Beta } \\
\end{array}$} & \multirow[b]{2}{*}{$t$} & \multirow[b]{2}{*}{ Sig. } \\
\hline & & B & Std. Error & & & \\
\hline \multirow[t]{3}{*}{1} & (Cons tant) & -3.336 & 3.722 & & -.896 & .384 \\
\hline & InSales & .457 & .579 & .174 & .790 & .442 \\
\hline & InProfit & 1.410 & .410 & .758 & 3.438 & .004 \\
\hline
\end{tabular}

Dari tabel 1 diperoleh, $\widehat{\ln e_{l}^{2}}=-3,336+0,457 \ln$ Sales $+1,41 \ln$ Profit. Jelas dari tabel Coefficient's diatas nilai Sig. dari variabel lnProfit $=0,004<0,05=$ $5 \%$, dan nilai $\left|t_{\text {hitung }}\right|=3,438>2,132=t_{\text {tabel }}$ sehingga $\mathrm{H}_{0}$ ditolak, ini berarti bahwa variansi galat dari variabel Profit bersifat heteroskedastisitas.

f. Simpulan: Data tersebut setelah dilakukan pengujian dengan metode park terindikasi terjadi heteroskedastisitas yang disebabkan variansi galat dari variable independennya yaitu Profit yang tidak konstan.

Pendeteksian dengan uji breusch pagan godfrey meliputi:

a. Meregresikanvariabel R \& D dengan variabeli ndependen Sales dan Profit

$$
R \widehat{\&} D=-13,956+0,01 \text { Sales }+0,24 \text { Profit }
$$

b. Mencarinilai $\sigma^{2} ; \sigma^{2}=\frac{\sum e_{i}^{2}}{n}=\frac{111012000.4}{18}=6167333,353$

c. Mencari nilai $\mathrm{p}$ dan diadakan uji regresi dengan variabel independennya sehingga dapat diketahui nilai ESS.

Sebagaimana pada Tabel 2.

\begin{tabular}{|c|c|c|c|c|c|c|}
\hline \multicolumn{7}{|c|}{ ANOVA } \\
\hline Model & & $\begin{array}{l}\text { Sum of } \\
\text { Squares }\end{array}$ & df & Mean Square & $\mathrm{F}$ & Sig. \\
\hline 1 & Regression & 39.763 & 2 & 19.882 & 8.228 & $.004^{\mathrm{a}}$ \\
\hline & Residual & 36.247 & 15 & 2.416 & & \\
\hline & Total & 76.011 & 17 & & & \\
\hline
\end{tabular}

Tabel 2.

a. Predictors: (Constant), Profit, Sales

b. Dependent Variable: $p$ 
Berdasarkan Tabel 2. dapat diketahui bahwa ESS $=39,763$, sehingga $\phi=\frac{1}{2} E S S=\frac{1}{2} \cdot 39,763=19,8815$

Langkah-langkah hipotesisnya adalah sebagai berikut:

(1) Rumusan hipotesis

$\mathrm{H}_{0}$ : variansi galat bersifat homoskedastisitas atau $\operatorname{var}\left(e_{i}\right)=\sigma^{2}$.

$\mathrm{H}_{1}$ : variansi galat bersifat heteroskedastisitas atau $\operatorname{var}\left(e_{i}\right) \neq \sigma^{2}$.

(2) Menentukan taraf signifikansi $\alpha=0,05$.

(3) Statistik uji $\chi^{2}$

$$
\chi_{\text {tabel }}^{2}=\chi_{(3-1 ; 0,05)}^{2}=\chi_{(2 ; 0,05)}^{2}=5,99
$$

(4) Kriteria pengujian

$$
\mathrm{H}_{0} \text { ditolak jika } \phi_{\text {hitung }}>\chi_{d f \text { tabel }}^{2}: d f=(\mathrm{m}-1)=3-1=2
$$

(5) Simpulan

Berdasarkan pengujian dengan uji Breusch Pagan Godfrey diperoleh $\phi_{\text {hitung }}=$ 19,8815 dan nilai $\chi_{(2 ; 0,05)}^{2}=5,99$.Jelas $\mathrm{H}_{0}$ ditolak karena $\phi_{\text {hitung }}=19,8815>5,99=\chi_{(2 ; 0,05)}^{2}$.

Sehingga data tersebut memiliki variansi galat bersifat heteroskedastisitas.

Contoh kasus data sampel ke-2, berdasarkan data tersebut akan dilakukan pengecekan apakah mengandung heteroskedastisitas atau tidak jika dideteksi dengan kedua uji tersebut. Diperoleh persamaan regresi

$$
\hat{Y}=1480+0,788 X
$$

Pendeteksian dengan uji park pada kasus ke-2, dengan menentukan $\alpha=0,05$, diperoleh $\frac{t_{0,05}(30-2)}{2}=2,101$. Selanjutnya melakukan langkah berikut:

(1) Meregresikan variabel $Y$ dengan variabel independen $X$. Diperoleh persamaan regresi $\hat{Y}=1480+0,788 X$

(2) Mengkuadratkan dan menghitung nilai log residualnya.

(3) Meregresikan variabel $\ln e_{i}^{2}$ dengan variabel independen $\ln X$.

Sebagaimana pada Tabel 3.

\section{Tabel 3.}

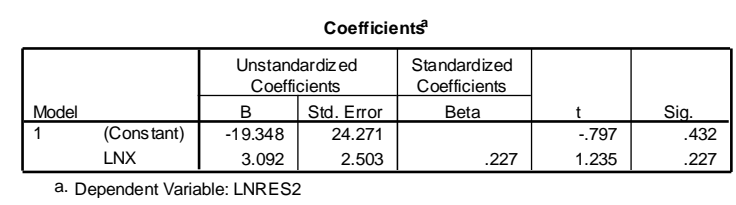

Dari Tabel 3 diperoleh persamaan $\widehat{\ln e_{l}^{2}}=-19,348+3,092 \ln X$ 
Jelas bahwa nilai Sig. dari variable $\ln X=0,227>0,05=5 \%$, dan nilai $\left|t_{\text {hitung }}\right|=1,235<2,101=t_{\text {tabel }}$

Sehingga $\mathrm{H}_{0}$ diterima, ini berarti bahwa variansi galat dari variable $X$ bersifat homoskedastisitas.

(4) Simpulan:

Data tersebut setelah dilakukan pengujian dengan uji park tidak terindikasi terjadi gejala heteroskedastisitas.

Pendeteksian dengan uji breusch pagan godfrey, pada kasus ke-2:

a. Meregresikanvariabel $Y$ denganvariabel $X, Y=1480+0,788 X$

b. Mencarinilai $\sigma^{2} ; \sigma^{2}=\frac{\sum \hat{e_{i}^{2}}}{n}=\frac{4996160}{30}=166538,667$

c. Mencari nilai $\mathrm{p}$ dan diadakan uji regresi dengan variabel independen $X$ sehingga dapat diketahui nilai $E S S$.

Sebagaimana pada Tabel 4 .

Tabel 4.

\begin{tabular}{|c|c|c|c|c|c|c|}
\hline \multicolumn{7}{|c|}{ ANOVA $^{b}$} \\
\hline & & $\begin{array}{l}\text { Sum of } \\
\text { Squares }\end{array}$ & df & Mean Square & $\mathrm{F}$ & Sig. \\
\hline \multirow[t]{3}{*}{1} & Regression & 7.735 & 1 & 7.735 & 5.778 & $.023^{\mathrm{a}}$ \\
\hline & Residual & 37.482 & 28 & 1.339 & & \\
\hline & Total & 45.217 & 29 & & & \\
\hline
\end{tabular}

Pada Tabel 4 di atas, dapat diketahui bahwa $E S S=7,735$. Sehingg

$\phi=\frac{1}{2} E S S=\frac{1}{2} \cdot 7,735=3,8675$

Langkah-langkah hipotesisnya adalah sebagai berikut:

Menentukan taraf signifikansi $\alpha=0,05$ dan statistik uji $\chi^{2}=\chi_{(2-1 ; 0,05)}^{2}=3,84$ dengan kriteria pengujian: $\mathrm{H}_{0}$ ditolak jika $\phi_{\text {hitung }}>\chi_{d f \text { tabel }}^{2}: d f=(\mathrm{m}-1)=2-1=1$. Berdasarkan pengujian dengan uji breusch pagan godfrey diperoleh $\phi_{\text {hitung }}=3,8675$ dan

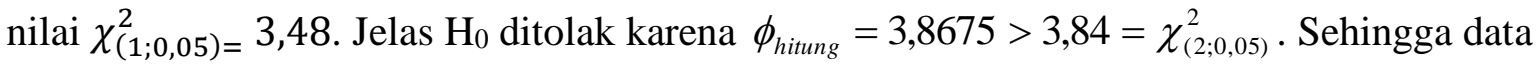
tersebut memiliki variansi galat bersifat heteroskedastisitas.

Contoh kasus data sampel ke-3, akan dilakukan pengecekan apakah mengandung heteroskedastisitas atau tidak jika dideteksi dengan kedua uji tersebut. Diperoleh persamaan regresi

$$
\hat{Y}=125,441+0,371 X_{1}-2,928 X_{2} .
$$

Pendeteksian dengan uji park sebagai berikut: 


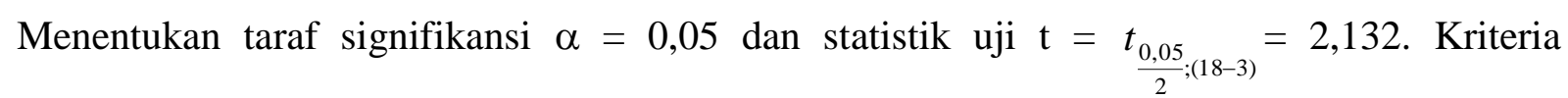
keputusan : $\mathrm{H}_{0}$ ditolak jika $\left|t_{\text {hitung }}\right|>t_{\frac{\alpha}{2} ;(n-p)}$, atau nilai Sig. $<\alpha$. Langkah selanjutnya meliputi: (1) meregresikan variabel $Y$ dengan variabel independen $X_{1}$ (GNP) dan $X_{2}$ (Indeks Harga Konsumen). Diperoleh persamaan regresi $\hat{Y}=125,441+0,371 X_{1}-2,928 X_{2}$, (2) kemudian mengkuadratkan dan menghitung nilai log residualnya, lalu (3) meregresikan variabel $\ln \hat{e_{i}^{2}}$ dengan variabel independen $\ln X_{1}$ dan $\ln X_{2}$. Sebagaimana pada Tabel 5.

\section{Tabel 5.}

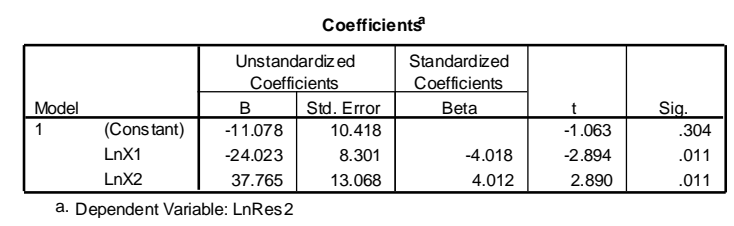

Diperoleh persamaan $\ln e_{i}^{2}=-11,078-24,023 \ln X_{1}+37,765 \ln X_{2}$

Jelas dari tabel Coefficient's diatas nilai Sig. dari variabel $\ln X_{1}=0,011=1,1 \%<0,05=$ $5 \%$, nilai $\left|t_{\text {hitung }}\right|=2,894>2,132=t_{\text {tabel }}$ dan nilai Sig. dari variabel $\ln X_{2}=0,011=1,1 \%<$ $0,05=5 \%$, dan nilai $\left|t_{\text {hitung }}\right|=2,890>2,132=t_{\text {tabel }}$, sehingga $\mathrm{H}_{0}$ ditolak, ini berarti bahwa variansi galat dari variabel $X_{1}$ dan $X_{2}$ bersifat heteroskedastisitas. Kesimpulannya data tersebut setelah dilakukan pengujian dengan uji Park terindikasi terjadi gejala heteroskedastisitas yang disebabkan variansi galat dari variabel independennya yaitu variabel $X_{1}$ dan $X_{2}$ yang tidak konstan.

Pendeteksian dengan uji breusch pagan godfrey, diperoleh persamaan regresi $\hat{Y}=125,441+0,371 X_{1}-2,928 X_{2}$. $\operatorname{dan} \sigma^{2}=\frac{\sum \hat{e_{i}^{2}}}{n}=\frac{111012000.4}{18}=6167333,353$.

Tabel 6.

\begin{tabular}{|c|c|c|c|c|c|c|}
\hline \multicolumn{7}{|c|}{ ANOVA } \\
\hline Model & & $\begin{array}{l}\text { Sum of } \\
\text { Squares }\end{array}$ & df & Mean Square & $\mathrm{F}$ & Sig. \\
\hline \multirow{3}{*}{1} & Regression & 21.552 & 2 & 10.776 & 8.044 & $.004^{\mathrm{a}}$ \\
\hline & Residual & 20.094 & 15 & 1.340 & & \\
\hline & Total & 41.646 & 17 & & & \\
\hline
\end{tabular}

b. Dependent Variable: $p$

Berdasarkan Tabel 6 dapat diketahui bahwa $E S S=21,552$ Sehingga $\phi=\frac{1}{2} \cdot 21,552=10,777$ dengan menentukan taraf signifikansi $\alpha=0,05$ dan statistik uji $\chi_{\text {tabel }}^{2}=\chi_{(3-1 ; 0,05)}^{2}=5,99$ dengan kriteria pengujian: $\mathrm{H}_{0}$ ditolak jika $\phi_{\text {hitung }}>\chi_{d f}^{2}$ tabel $: d f=(\mathrm{m}-1)=3-1=2$ diperoleh simpulan berdasarkan pengujian dengan uji breusch pagan godfrey diperoleh $\phi_{\text {hitung }}=10,777$ 
dan nilai $\chi_{(2 ; 0,05)}^{2}=5,99$. Jelas $\mathrm{H}_{0}$ ditolak karena $\phi_{\text {hitung }}=10,777>5,99=\chi_{(2 ; 0,05)}^{2}$ sehingga data tersebut memiliki variansi galat.

Setelah diadakan pendeteksian heteroskedastisitas dengan dua uji statistik pada masing-masing kasus. Diketahui bahwa pada sampel ke-2 dideteksi dengan uji Park tidak terindikasi terjadi heteroskedastisitas. Namun saat pendeteksian dengan uji breusch pagan godfrey terindikasi. Sedangkan untuk contoh kasus lain terdeteksi heteroskedastisitas baik dengan uji park maupun uji breusch pagan godfrey. Menghitung nilai Mean Absolute Error (MAE) dan Mean Square Error (MSE) pada masing masing sampel, sehingga dapat diketahui uji manakah yang memiliki nilai (MSE) error kecil. Setelah dilakukan perhitungan dapat diketahui nilai MAE dan MSE sebagaimana pada Tabel 7.

Tabel 7. Nilai Mean Absolute Error (MAE) dan Mean Square Error (MSE)

\begin{tabular}{ccccc}
\hline \multirow{2}{*}{ Sampel } & & $\begin{array}{c}\text { Pers } \\
\text { Regresi }\end{array}$ & Uji Park & $\begin{array}{c}\text { Metode Breusch } \\
\text { Pagan }\end{array}$ \\
\hline \multirow{2}{*}{$\mathbf{n}$} & MAE & 1650.2298 & 24.69547 & 1.469303 \\
& MSE & 6170257.14 & 653.4506 & 7.507899 \\
2 & MAE & 327.89493 & 1.854037 & 2.917 \\
& MSE & 166789.63 & 5.552308 & 10.01614 \\
\multirow{3}{*}{} & MAE & 9.3814 & 1.223353 & 0.893311 \\
& MSE & 134.2781 & 2.074186 & 1.314393 \\
\hline
\end{tabular}

Dari Tabel 7 diperoleh dari tiga data yang terdeteksi masalah heteroskedastisitas dua diantaranya contoh kasus data terdeteksi baik dengan menggunakan uji park maupun uji breusch pagan godfrey, dan satu data diantaranya terdeteksi dengan uji breusch pagan godfrey. Uji breusch pagan godfrey memiliki nilai MSE lebih kecil dibandingkan dengan uji park. Sehingga dapat disimpulkan bahwa uji breusch pagan godfrey lebih efektif dibandingkan dengan uji park. Pendeteksian heteroskedastisitas dengan uji breusch pagan godfrey lebih efektif dibanding dengan uji park, karena empat dari lima data memiliki nilai mean square error (MSE) lebih kecil dari uji park sehingga lebih mendekati kebenaran.

\section{SIMPULAN DAN SARAN}

Berdasarkan hasil penelitian pada simulasi tiga data yang telah dilakukan, diperoleh data terdeteksi masalah heteroskedastisitas, dengan dua contoh kasus data terdeteksi baik menggunakan uji park maupun uji breusch pagan godfrey, dan satu data terdeteksi dengan uji breusch pagan godfrey. Diperoleh mengenai gambaran mengenai pendeteksian heteroskedastisitas melalui uji park dan uji breusch pagan godfrey pada analisis regresi, bahwa pendeteksian heteroskedastisitas dengan uji breusch pagan godfrey lebih efektif dibanding dengan uji park. Dikarenakan empat dari lima data memiliki nilai mean square error (MSE) lebih kecil dari uji park sehingga lebih mendekati kebenaran. Adapun sehubungan dengan hasil penelitian ini sebaiknya dalam melakukan pendeteksian heteroskedastisitas dengan menggunakan uji breusch pagan godfrey karena lebih efektif dibandingkan uji park. 


\section{DAFTAR PUSTAKA}

Birkes, D. d. (2011). Nonparametric Regression. Sohravardi: Persian Philosopher, 11551191.

Davino, C. M. (2014). Quantile Regression: Understanding How and Why. Review of Economics and Statistics , 22-62.

Farizal, A. R. (2014). Model Peramalan Konsumsi Bahan Bakar Jenis Premium Di Indonesia Dengan Regresi Linier Berganda. Jurnal Ilmiah Teknik Industri , 13 (2), 1412-6869.

Ghozali, Imam. (2009). Ekonometrika Teori, Konsep, dan Aplikasi dengan SPSS 17. Semarang: Badan Penerbit Universitas Diponegoro.

Hajarisman, N. (2012). Penaksiran Parameter Model Regresi Beta untuk Memodelkan Data Proporsi. Statistika, 12 (1), 9-18.

Hollander, M. D. (2015). Regression Problems. Review of Economics and Statistics , 451-494.

Ivan, K. C. (2016). Analisis Model Regresi Nonparametrik Sirkular Linear Berganda. EJurnal Matematika , 5 (2), 52-58.

Muliawan, A. D. (2015). A Review On The Use Of Regression Analysis In Studies Of Audit Quality. Jurnal Tata Kelola \& Akuntabilitas Keuangan Negara , 1 (1), 107-127.

Nurlaila, Z. M. (2017). Penerapan Metode Newey West Dalam Mengoreksi Standard Error Ketika Terjadi Heteroskedastisitas dan Autokorelasi Pada Aisnalis Regresi. E-Jurnal Matematika , 6 (1), 7-14.

Pradawati, P. S. (2013). Penerapan Regresi Binomial Negatif Untukl Mengatasi Overdispersi Pada Regresi Poisson. E-Jurnal Matematika , 2 (2), 6-10.

Ratnasari, N. P. (2014). Aplikasi Regresi Data Panel Dengan Pendekatan Fixed Effect Model (Studi Kasus: PT PLN Gianyar)v. E-Jurnal Matematika , 3 (1), 1-7.

Sunarto. (2015). Pengaruh Kualitas Produk Terhadap Keputusan Pembelian Pada Toko Kerjinan Kulit Kartika Magetan. Equilibrium , 3 (2), 191-205.

Tayeb, T. (2012). Efektivitas Metode New Stepwise Dalam Pemilihan Variabel Pada Model Regresi Ganda. Lentera Pendidikan, 15 (2), 161-174.

Uthami, I. A. (2013). Regresi Kuantil Median Untuk Mengatasi Heteroskedastisitas Pada Analisis Regresi. e-Jurnal Matematika , 2 (1), 6-13. 